\title{
Bilateral versus unilateral antegrade cerebral perfusion in total arch replacement for type A aortic dissection
}

\author{
Guang Tong, MD, PhD, ${ }^{\mathrm{a}}$ Ben Zhang, MD, PhD, ${ }^{\mathrm{a}}$ Xuan Zhou, MD, PhD, ${ }^{\mathrm{b}}$ Ye Tao, MD, PhD, ${ }^{\mathrm{c}, \mathrm{d}}$ \\ Tao Yan, MD, PhD, ${ }^{\mathrm{a}}$ Xianyue Wang, MD, ${ }^{\mathrm{a}}$ Hua Lu, MD, PhD, ${ }^{\mathrm{a}}$ Zhongchan Sun, MD, PhD, ${ }^{\mathrm{e}}$ and \\ Weida Zhang, MD $^{\mathrm{a}}$
}

\begin{abstract}
Background: Antegrade cerebral perfusion (ACP) is the most widely used cerebral protection strategy for complex aortic repair and includes unilateral (u-ACP) and bilateral (b-ACP) techniques. The superiority of b-ACP over $\mathrm{u}-\mathrm{ACP}$ has been the subject of much debate. Focusing on type A aortic dissection requiring total arch replacement, we investigated the clinical effects of b-ACP versus u-ACP.
\end{abstract}

Methods: Between September 2006 and August 2014, 203 patients presenting with type A aortic dissection (median age, $51.0 \pm 13$ years; range, 17-72 years; 128 males) underwent total aortic arch replacement with hypothermic circulatory arrest. ACP was used in all patients, including $\mathrm{u}-\mathrm{ACP}$ in $82(40.3 \%)$ and b-ACP in $121(59.7 \%)$.

Results: There was no significant difference between the u-ACP and b-ACP groups in terms of cardiopulmonary bypass (CPB) time, cross-clamp time, or circulatory arrest time. Overall 30-day mortality was comparable in the 2 groups (11.6\% for b-ACP vs $20.7 \%$ for u-ACP; $P=.075$ ). The prevalence of postoperative permanent neurologic dysfunction (PND) was comparable as well $(8.4 \%$ vs $16.9 \% ; P=.091)$. Mean ventilation time was lower in the b-ACP group $(95.5 \pm 45.25$ hours vs $147.0 \pm 82$ hours; $P<.001)$. Mean lengths of stay in the intensive care unit and the hospital overall were comparable in the 2 groups (intensive care unit: $16 \pm 17.75$ days vs $17 \pm 11.5$ days, $P=.454$; hospital: $26.5 \pm 20.6$ days vs $24.8 \pm 10.3$ days, $P=.434$ ). The $P$ values from logistic regression models indicated that in the 2 groups combined, CPB time and circulatory arrest time were independent risk factors for both mortality and PND.

Conclusions: In this, the first published study focusing on the efficacy of u-ACP and b-ACP in total arch replacement for type A aortic dissection, the b-ACP group did not demonstrate significantly lower 30-day mortality or PND rate compared with the u-ACP group. Future large-sample studies are warranted to thoroughly examine this critical issue. (J Thorac Cardiovasc Surg 2017;154:767-75)

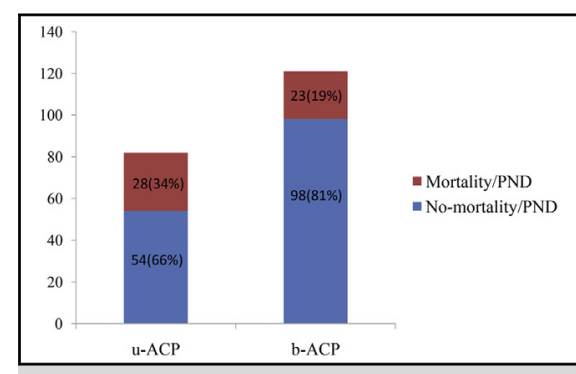

Thirty-day mortality and PND in the $\mathrm{u}-\mathrm{ACP}$ and b-ACP groups.

\section{Central Message}

In this study of unilateral antegrade cerebral perfusion (u-ACP) and bilateral antegrade cerebral perfusion (b-ACP) in total arch replacement for type A aortic dissection, clinical outcomes of u-ACP and b-ACP groups were compared.

\section{Perspective}

In this study comparing unilateral antegrade cerebral perfusion (u-ACP) and bilateral antegrade cerebral perfusion (b-ACP) in total arch replacement for type A aortic dissection, the b-ACP group did not exhibit significantly reduced mortality or permanent neurologic dysfunction. b-ACP did not prolong CPB, cardiac arrest, or circulatory arrest time. Future large-sample, randomized, multicenter studies are warranted to thoroughly compare b-ACP and $\mathrm{u}-\mathrm{ACP}$.

See Editorial Commentary page 776

See Editorial page 765 .

\footnotetext{
From the Departments of ${ }^{\mathrm{a} C}$ Cardiovascular Surgery and ${ }^{\mathrm{b}}$ Cardiology, Guangzhou General Hospital of Guangzhou Military Command, Guangzhou, China; ${ }^{\mathrm{c} D e p a r t m e n t}$ of Ophthalmology, General Hospital of Chinese PLA, Ophthalmology and Visual Science Key Lab of PLA, Beijing, China; ${ }^{\mathrm{d}}$ Department of Ophthalmology, Beidaihe Hospital of Chinese PLA, Beidaihe, China; and ${ }^{\mathrm{e}}$ Department of Cardiology, Xijing Hospital, Fourth Military Medical University, Xi'an, China.

This work was supported by the National Natural Science Foundation of China (Grants 81500183, to G.T., 81500298, to B.Z., and 81400366, to Z.S.), Military Medical Science Foundation (Grant 14QNP043, to X.Z.), Pearl River Science and Technology Nova Program of Guangzhou (Grant 201610010094, to B.Z.), and the Natural Science Foundation of Guangdong Province (Grants 2014A030310473, to B.Z., and 2015A030310116, to X.Z.).
}

G.T., B.Z., and X.Z. contributed equally to this work.

Received for publication Aug 31, 2016; revisions received Jan 19, 2017; accepted for publication Feb 17, 2017; available ahead of print April 15, 2017.

Address for reprints: Weida Zhang, MD, Department of Cardiovascular Surgery, Guangzhou General Hospital of Guangzhou Military Command, Guangzhou, Guangdong Province 510010, China (E-mail: weidazhang1958@gmail.com).or Zhongchan Sun, MD, PhD, Department of Cardiology, Xijing Hospital, Fourth Military Medical University, Xi'an, China (E-mail: sunzc1985@gmail.com). 0022-5223/\$36.00

Copyright (C) 2017 by The American Association for Thoracic Surgery http://dx.doi.org/10.1016/j.jtcvs.2017.02.053 


$\begin{array}{ll}\text { Abbreviations and Acronyms } \\ \text { ACP } & =\text { antegrade cerebral perfusion } \\ \text { b-ACP } & =\text { bilateral antegrade cerebral perfusion } \\ \text { CABG } & =\text { coronary artery bypass grafting } \\ \text { COPD } & =\text { chronic obstructive pulmonary } \\ & \text { disease } \\ \text { CPB } & =\text { cardiopulmonary bypass } \\ \text { CT } & =\text { computed tomography } \\ \text { GERAADA }= & \text { German Registry for Acute Aortic } \\ & \text { Dissection Type A } \\ \text { IRAD } & =\text { International Registry of Aortic } \\ & \text { Dissection } \\ \text { MRI } & =\text { magnetic resonance imaging } \\ \text { PND } & =\text { permanent neurologic dysfunction } \\ \text { SET } & =\text { stented elephant trunk } \\ \text { TND } & =\text { temporary neurologic dysfunction } \\ \text { u-ACP } & =\text { unilateral antegrade cerebral } \\ & \text { perfusion }\end{array}$

Scanning this QR code will take you to a procedural video.

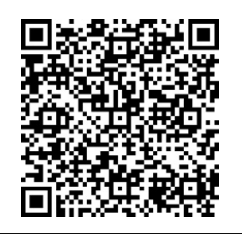

Despite advances in surgical therapy, operative mortality for type A aortic dissection remains high. ${ }^{1}$ Neurologic dysfunction is a common complication of open aortic arch reconstructive surgery, with a reported incidence ranging from $5.5 \%$ to $33.3 \% .^{2}$ Hypothermia with adjunctive antegrade cerebral perfusion (ACP) has been shown to improve outcomes and reduce neurologic complications and being increasingly used in surgery to reconstruct the aortic $\operatorname{arch}^{2,3}$ The superiority of unilateral ACP (u-ACP) over bilateral ACP (b-ACP) has been a subject of debate for years ${ }^{4,5}$; however, to date only a few published studies have focused on the effects of different cerebral perfusion strategies in type A aortic dissection., ${ }^{5,6}$ Total arch replacement, the most radical repair strategy, is indicated in some patients with type A aortic dissection ranging from $5 \%$ to $53 \%$, depending on differences in patient demographics and management strategies. ${ }^{7-9}$ Up to now, the use of u-ACP versus b-ACP has not been studied specifically in patients with type A aortic dissection requiring total arch replacement.

The aims of the present study were to report our clinical experience of selective cerebral perfusion for total arch replacement for type A aortic dissection, and to compare the protective effects of $\mathrm{b}-\mathrm{ACP}$ and $\mathrm{u}-\mathrm{ACP}$ in combination with hypothermic circulatory arrest.

\section{PATIENTS AND METHODS}

Between September 2006 and June 2014, a total of 203 patients with type A dissection underwent total arch replacement at Guangzhou General Military Hospital (Guangzhou, China) were enrolled into this study. Of all 351 patients with type A aortic dissection, total arch replacement was performed if 1 of the following was shown on computed tomography (CT) angiography: arch tear (primary or secondary tear), carotid dissection or occlusion, circumferential arch dissection, or aneurysmal arch. Ascending aorta or hemiarch replacement was performed when total arch replacement was not indicated.

Data were collected from a prospectively maintained database. The study protocol was approved by the Committee for the Protection of Human Subjects at the Guangzhou General Hospital of Guangzhou Military Command. Because this was a retrospective study, the requirement for informed consent was waived. All patients who underwent total arch replacement received ACP, including $82(40.4 \%)$ in the u-ACP group and $121(59.6 \%)$ in the b-ACP group. Further characteristic and preoperative data are summarized in Table 1 . The concomitant procedures in the 2 groups are compared in Table 2.

\section{Surgical Technique}

Our surgical technique for type A aortic dissection included total cardiopulmonary bypass $(\mathrm{CPB})$, moderate hypothermia, circulatory arrest, and $\mathrm{u}-$ ACP or b-ACP. Monitoring included central venous pressure, bilateral radial artery pressure, 5-lead electrocardiography, nasopharyngeal and rectal temperature, and intermittent arterial blood gas analysis. Cerebral saturation was monitored using near-infrared spectroscopy (NIRO 300: Hamamatsu Phototonics, Hamamatsu, Japan). Systolic arterial blood pressure was maintained around 70 to $80 \mathrm{mmHg}$ intraoperatively. The nasopharyngeal temperature at the start of circulatory arrest was $24^{\circ} \mathrm{C}$ at the beginning of the study period and increased gradually to $26^{\circ} \mathrm{C}$. The remaining strategies remained largely constant during the study period. Before September 2009, u-ACP combined with hypothermic circulatory arrest was used for cerebral protection. In September 2009, b-ACP combined with hypothermic circulatory arrest was initiated, and both techniques were used from that point until the end of the study period. Right axillary artery cannulation was performed for CPB.

In the b-ACP group, cerebral perfusion was performed through the right axillary artery and the left common carotid artery. After initiation of CPB and patient cooling, the left common carotid artery was cross-clamped and transected, and anastomosis to the 4-branched graft (Boston Scientific, Boston, Mass) was performed. The left hemisphere was perfused via the 4-branched graft connected to a branch of the arterial pump. When the temperature reached $30^{\circ} \mathrm{C}$, the ascending aorta was cross-clamped, the proximal ascending aorta was opened longitudinally, and cold-blood cardioplegic solution was infused directly into the coronary ostia. When the nasopharyngeal temperature reached $24^{\circ} \mathrm{C}$ to $26^{\circ} \mathrm{C}$, circulatory arrest was initiated by clamping the proximal innominate artery and the left subclavian artery. Flows used for ACP were 10 to $15 \mathrm{~mL} / \mathrm{kg} / \mathrm{min}$, with perfusion pressures of 40 to $50 \mathrm{~mm} \mathrm{Hg}$. Stented elephant trunk (SET; MicroPort Medical Co Ltd, Shanghai, China), which has been shown to reduce the need for reintervention while adding little operative time, ${ }^{10,11}$ was routinely inserted into the proximal descending aorta. The distal end of the graft was firmly attached to the descending aorta, incorporating the SET. Systemic circulation was restarted via the perfusion limb of the 4branch prosthetic graft. The indicated aortic root procedure was performed, followed by anastomosis of the aortic root to the prosthetic graft. Finally, anastomoses of the innominate artery and left subclavian artery to the 4branched prosthetic graft were performed (Video 1).

In the u-ACP group, right axillary artery cannulation was performed for $\mathrm{CPB}$ and u-ACP. After cross-clamping of the ascending aorta, the indicated aortic root procedure was performed. When the nasopharyngeal temperature reached $24^{\circ} \mathrm{C}$ to $26^{\circ} \mathrm{C}$, circulatory arrest was initiated by clamping the proximal innominate artery, the left common carotid artery, and the left 
TABLE 1. Preoperative characteristics

\begin{tabular}{|c|c|c|c|c|}
\hline Characteristic & Total $(\mathbf{n}=\mathbf{2 0 3})$ & $\mathbf{u}-\mathbf{A C P}(\mathbf{n}=\mathbf{8 2})$ & b-ACP $(n=121)$ & $P$ value \\
\hline Age $(y)$, mean \pm SD & $51.0 \pm 13$ & $53 \pm 14$ & $47 \pm 1275$ & .205 \\
\hline Months to start of cohort, mean \pm SD & $43 \pm 29$ & $42 \pm 32$ & $44 \pm 27.5$ & .208 \\
\hline Males, n (\%) & $128(63.1)$ & $55(67.1)$ & $73(60.3)$ & .329 \\
\hline Females, n $(\%)$ & $75(36.9)$ & $27(32.9)$ & $48(39.7)$ & .436 \\
\hline Hypertension, n (\%) & $174(85.7)$ & $74(90.2)$ & $100(82.6)$ & .129 \\
\hline Diabetes mellitus, $\mathrm{n}(\%)$ & $64(31.5)$ & $25(30.5)$ & $39(32.2)$ & .793 \\
\hline Smoking, n (\%) & $109(53.7)$ & $44(53.7)$ & $65(53.7)$ & .993 \\
\hline Previous CVA, n (\%) & $3(1.5)$ & $2(2.4)$ & $1(0.8)$ & .350 \\
\hline Peripheral vascular disease, $\mathrm{n}(\%)$ & $14(6.1)$ & $7(8.5)$ & $7(5.8)$ & .448 \\
\hline Renal dysfunction, $\mathrm{n}(\%)^{*}$ & $25(12.3)$ & $10(12.2)$ & $15(12.4)$ & .966 \\
\hline COPD, n $(\%)$ & $3(1.5)$ & $2(2.4)$ & $1(0.8)$ & .350 \\
\hline Marfan syndrome, n (\%) & $13(6.4)$ & $5(6.1)$ & $8(6.6)$ & .883 \\
\hline Bicuspid aortic valve, $\mathrm{n}(\%)$ & $8(3.9)$ & $3(3.7)$ & $5(4.1)$ & .865 \\
\hline Dissection $<24 \mathrm{~h}, \mathrm{n}(\%)$ & $135(66.5)$ & $54(65.9)$ & $81(66.9)$ & .812 \\
\hline Dissection $>24 \mathrm{~h}, \mathrm{n}(\%)$ & $68(33.5)$ & $28(34.1)$ & $40(33.1)$ & .945 \\
\hline Preoperative neurologic complications, n (\%) & $11(5.4)$ & $4(4.9)$ & $5(5.8)$ & .779 \\
\hline Pericardial effusion/tamponade, n (\%) & $28(13.8)$ & $11(13.4)$ & $17(14.0)$ & .898 \\
\hline Hemodynamic instability, n (\%) & $12(5.9)$ & $5(6.1)$ & $7(5.8)$ & .926 \\
\hline Intubated on arrival, $\mathrm{n}(\%)$ & $16(7.9)$ & $7(8.5)$ & $9(7.4)$ & .776 \\
\hline
\end{tabular}

$u$-ACP, Unilateral antegrade cerebral perfusion; $b-A C P$, bilateral antegrade cerebral perfusion; $S D$, standard deviation; $C V A$, cerebrovascular accident; $C O P D$, chronic obstructive pulmonary disease. $* A$ serum creatinine level $>2.0 \mathrm{mg} / \mathrm{mL}$ is considered to indicate renal dysfunction.

subclavian artery. The SET was inserted, and the sequence of anastomosis to the prosthetic graft was as follows: descending aorta, left common carotid artery, proximal aortic stump, innominate artery, and left subclavian artery.

\section{Statistical Analysis}

The outcome measures were 30-day mortality, permanent neurologic dysfunction (PND), temporary neurologic dysfunction (TND), renal failure, tracheostomy, and readmission to the operating room for bleeding and mediastinal infection. TND was defined as the presence of reversible postoperative confusion, agitation, transient delirium or motor deficit with normal findings on $\mathrm{CT}$ scan and resolution of all symptoms before discharge. PND was defined as the presence of new focal (stroke) or global (coma) permanent neurologic dysfunction and confirmed by CT or MRI. Pearson's $\chi^{2}$ test was used for dichotomous variables. Normally distributed continuous variables were presented as mean \pm standard deviation and compared with Student's $t$ test. Non-normally distributed data was displayed as median \pm interquartile range and compared using the MannWhitney $U$ test. Blood product utilization was broken down to groups and compared with rank-sum test. The significance level was set at $P<.05$. Major perioperative characteristics and outcomes of those operated within 24 hours after onset of symptom were compared separately. To predict the probabilities of mortality, we performed bivariate logistic regressions using potential covariates of interest including age, female gender, renal dysfunctions, COPD, time at surgery to the start of cohort, acute type A dissection, pericardial effusion/tamponade, hemodynamic instability, CABG, type of cerebral perfusion, CPB time, cross-clamp time, and circulatory arrest time. ${ }^{5,12-16}$ For PND, potential covariates of interest included age, acute type A dissection, hemodynamic instability, time to start of the cohort, type of cerebral perfusion, CPB time, crossclamp time, and circulatory arrest time. Potential covariates of interest, including age, acute type A dissection, time to start of cohort, type of cerebral perfusion, preoperative renal dysfunction, CPB time, cross-clamp time, and circulatory arrest time, were used for predicting the probability of postoperative renal failure. In addition, multivariate logistic regression analysis was performed to further identify independent predictors of adverse outcomes. Variables with a $P$ value $<.10$ in bivariate analysis were included in forward multivariate logistic regression models. Statistical analyses were performed using SPSS 22.0 (IBM, Armonk, NY).

\section{RESULTS}

\section{Intraoperative Data}

Table 2 presents concomitant procedures in the u-APC and b-APC groups. Rates of use of concomitant SET, Bentall operation, Valsalva sinus reconstruction, aortic valve resuspension, and coronary artery bypass grafting were not significantly different in the 2 groups.

As shown in Table 3, there were no significant differences in CPB time, cross-clamp time, circulatory arrest time, intensive care unit time, in-hospital time, packed red blood cell transfusion, serum transfusion, nasopharyngeal temperature, and rectal temperature between the $\mathrm{u}$-ACP and

TABLE 2. Surgical strategies

\begin{tabular}{|c|c|c|c|c|}
\hline Variable & Total $(n=203)$ & $\mathrm{u}-\mathrm{ACP}(\mathrm{n}=\mathbf{8 2})$ & b-ACP $(n=121)$ & $P$ valu \\
\hline SET, n $(\%)$ & $199(98.0)$ & $80(97.6)$ & $119(98.3)$ & 1.000 \\
\hline Bentall operation, $\mathrm{n}(\%)$ & $39(19.2)$ & $19(23)$ & $20(16.2)$ & .239 \\
\hline Valvasa sinus reconstruction, $\mathrm{n}(\%)$ & 40 (19.7) & $17(20.3)$ & $23(19.0)$ & .762 \\
\hline Aortic valve resuspension, $\mathrm{n}(\%)$ & $10(4.9)$ & $4(4.9)$ & $6(5.0)$ & 1.000 \\
\hline Coronary artery bypass grafting, $\mathrm{n}(\%)$ & $25(12.3)$ & $11(13.4)$ & 14 (11.6) & .695 \\
\hline
\end{tabular}

$u-A C P$, Unilateral antegrade cerebral perfusion; $b-A C P$, bilateral antegrade cerebral perfusion; $S E T$, stented elephant trunk. 


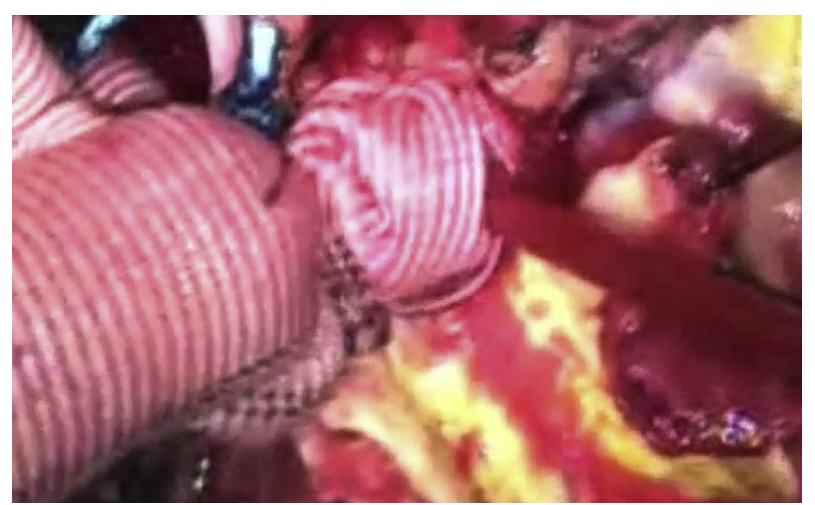

VIDEO 1. Total arch replacement using bilateral ACP. Right axillary artery and right atrium cannulation were performed for $\mathrm{CPB}$. After initiation of CPB and patient cooling, the left common carotid artery was crossclamped and transected, and the anastomosis to the 4-branched graft was performed. The left hemisphere was perfused via the 4-branched graft connected to a branch of the arterial pump. When temperature reached $30^{\circ} \mathrm{C}$, the ascending aorta was cross-clamped, the proximal ascending aorta was opened longitudinally, and cold-blood cardioplegic solution was infused directly into the coronary ostia. When the nasopharyngeal temperature reached $24^{\circ} \mathrm{C}$ to $26^{\circ} \mathrm{C}$, circulatory arrest was initiated by clamping the proximal innominate artery and the left subclavian artery. Flows used for ACP were 10 to $15 \mathrm{~mL} / \mathrm{kg} / \mathrm{min}$, with perfusion pressures of 40 to $50 \mathrm{~mm} \mathrm{Hg}$. The SET, which has been shown to reduce need for reintervention with little additional operating time, was inserted into the proximal descending aorta. The distal end of the graft was firmly attached to the descending aorta, incorporating the SET. Systemic circulation was restarted via the perfusion limb of the 4-branch prosthetic graft. The indicated aortic root procedure was performed, followed by anastomosis of the aortic root to the prosthetic graft. Finally, anastomoses of the innominate artery and left subclavian artery to the 4-branched prosthetic graft were performed. Video available at: http://www.jtcvsonline.org/article/S0022-5223(17)30415-4/addons.

b-ACP groups. As shown in Table 4, concomitant procedures and major intraoperative data in patients who underwent surgery within 24 hours of symptom onset were also comparable in the 2 groups.

\section{Mortality}

Overall 30 -day mortality was $20.7 \%$ for the u-ACP group and $11.6 \%$ for the b-ACP group $(P=.075)$ (Figure 1, Table 5). In the u-ACP group, causes of death were multiple organ failure in 8 patients, sepsis in 4 patients, and low cardiac output syndrome in 5 patients. In the b-ACP group, causes of death were multiple organ failure in 7 patients, low cardiac output syndrome in 5 patients, and sepsis in 2 patients. In the bivariate logistic regression model, age, female sex, preoperative renal dysfunction, acute type A dissection, pericardial effusion/tamponade, CPB time, cross-clamp time, and circulatory arrest time were predictive of mortality (Table 6). Furthermore, multivariable regression identified CPB time and circulatory arrest time as independent predictors of mortality. For patients undergoing surgery within 24 hours after symptom onset, the mortality rate was $22.2 \%$ in the u-ACP group and $11.1 \%$ in the b-ACP group $(P=.081)$ (Table 4$)$.

\section{Morbidities}

Postoperative neurologic dysfunction was divided into TND and PND. TND was observed in 6 of 65 surviving patients $(9.2 \%)$ in the u-ACP group and in 5 of $107(4.7 \%)$ in the $\mathrm{b}$-ACP group $(P=.236)$. PND was observed in 11 of 65 patients $(16.9 \%)$ in the u-ACP group and in 9 of $107(8.4 \%)$ in the b-ACP group $(P=.091)$ (Figure 1). Tracheostomy was performed in 11 of 65 patients $(16.9 \%)$ in the $\mathrm{u}-\mathrm{ACP}$ group and in 4 of $107(3.7 \%)$ in the b-ACP group $(P=.003)$. Ventilation times were longer in the $\mathrm{u}-\mathrm{ACP}$ group. In the univariate logistic regression model, age, acute type A dissection, CPB time, and circulatory arrest time were predictive of PND (Table 6). Furthermore, multivariate logistic regression identified CPB time and circulatory arrest time as independent predictors of PND (Table 7). The rates of postoperative renal failure were comparable in

TABLE 3. Perioperative data

\begin{tabular}{|c|c|c|c|c|}
\hline Variable & Total $(\mathbf{n}=\mathbf{2 0 3})$ & $\mathbf{u}-\mathbf{A C P}(\mathbf{n}=\mathbf{8 2})$ & b-ACP $(n=121)$ & $P$ value \\
\hline $\mathrm{CPB}$ time $(\mathrm{min})$, mean $\pm \mathrm{SD}$ & $198 \pm 53$ & $200.0 \pm 53.75$ & $204 \pm 42.5$ & .197 \\
\hline Cross-clamp time $(\mathrm{min})$, mean $\pm \mathrm{SD}$ & $101 \pm 36$ & $103.0 \pm 30.25$ & $105.0 \pm 31.5$ & .545 \\
\hline Circulatory arrest time $(\mathrm{min})$, mean $\pm \mathrm{SD}$ & $24 \pm 8$ & $23.0 \pm 9.25$ & $24.0 \pm 8.0$ & .893 \\
\hline Nasopharyngeal temperature $\left({ }^{\circ} \mathrm{C}\right)$, mean $\pm \mathrm{SD}$ & $23.6 \pm 1.1$ & $23.7 \pm 1.1$ & $23.6 \pm 1.1$ & .504 \\
\hline Rectal temperature $\left({ }^{\circ} \mathrm{C}\right)$, mean $\pm \mathrm{SD}$ & $25.9 \pm 1.3$ & $25.9 \pm 1.4$ & $26.0 \pm 1.3$ & .463 \\
\hline Transfused RBC units, $\mathrm{n}$ & & & & .391 \\
\hline$\leq 10$ & 56 & 21 & 35 & \\
\hline $11-20$ & 76 & 38 & 38 & \\
\hline $21-30$ & 66 & 22 & 44 & \\
\hline$>30$ & 5 & 1 & 2 & \\
\hline Transfused serum units, $\mathrm{n}$ & & & & .840 \\
\hline$\leq 5$ & 2 & 1 & 1 & \\
\hline $6-10$ & 109 & 43 & 66 & \\
\hline $11-15$ & 85 & 33 & 52 & \\
\hline
\end{tabular}

$u$ - $A C P$, Unilateral antegrade cerebral perfusion; $b-A C P$, bilateral antegrade cerebral perfusion; $C P B$, cardiopulmonary bypass; $S D$, standard deviation; $I C U$, intensive care unit; $R B C$, red blood cell. 
TABLE 4. Major preoperative characteristic, perioperative data, and outcomes of acute (<24 h) type A aortic dissection

\begin{tabular}{|c|c|c|c|c|}
\hline Variable & Total $(\mathbf{n}=135)$ & $\mathrm{u}-\mathrm{ACP}(\mathrm{n}=\mathbf{5 4})$ & $\mathbf{b}-\mathbf{A C P}(\mathbf{n}=\mathbf{8 1})$ & $P$ value \\
\hline Age $(y)$, mean $\pm S D$ & $47 \pm 15$ & $45 \pm 15$ & $51 \pm 14$ & .196 \\
\hline Months to start of cohort, mean $\pm \mathrm{SD}$ & $43 \pm 29.25$ & $42 \pm 33$ & $44.5 \pm 27.75$ & .377 \\
\hline Male, n (\%) & $93(66.9)$ & $36(66.7)$ & $57(70.4)$ & .649 \\
\hline Female, $\mathrm{n}(\%)$ & $42(31.1)$ & $18(33.3)$ & $24(29.6)$ & .756 \\
\hline Hypertension, $\mathrm{n}(\%)$ & $112(82.9)$ & $47(87.0)$ & $65(80.2)$ & .304 \\
\hline Preoperative neurologic complications, $\mathrm{n}(\%)$ & $6(4.4)$ & $3(5.6)$ & $3(3.7)$ & .683 \\
\hline Pericardial effusion/tamponade, $\mathrm{n}(\%)$ & $17(12.6)$ & $7(12.9)$ & $10(12.3)$ & .916 \\
\hline Hemodynamic instability, $\mathrm{n}(\%)$ & $7(5.2)$ & $3(5.6)$ & $4(4.9)$ & 1.000 \\
\hline Intubated on arrival, $\mathrm{n}(\%)$ & $10(7.4)$ & $4(7.4)$ & $6(7.4)$ & 1.000 \\
\hline SET, n $(\%)$ & $133(98.5)$ & $53(98.1)$ & $80(98.8)$ & 1.000 \\
\hline Bentall operation, $\mathrm{n}(\%)$ & $27(20.0)$ & $10(18.5)$ & $17(20.9)$ & .725 \\
\hline Valvasa sinus reconstruction, $\mathrm{n}(\%)$ & $25(18.5)$ & $9(16.7)$ & $16(19.8)$ & 651 \\
\hline Aortic valve resuspension, $\mathrm{n}(\%)$ & $7(5.2)$ & $2(3.7)$ & $5(6.2)$ & .702 \\
\hline Coronary artery bypass grafting, $\mathrm{n}(\%)$ & 17 (12.6) & $6(11.1)$ & $11(13.6)$ & .672 \\
\hline $\mathrm{CPB}$ time $(\mathrm{min})$, mean $\pm \mathrm{SD}$ & $208.5 \pm 29.6$ & $210.7 \pm 28.9$ & $206.8 \pm 30.1$ & .259 \\
\hline Cross-clamp time (min), mean \pm SD & $102 \pm 32$ & $108.5 \pm 31.75$ & $95 \pm 25.5$ & .593 \\
\hline Circulatory arrest time (min), mean $\pm \mathrm{SD}$ & $24 \pm 8$ & $25 \pm 6$ & $23 \pm 6$ & .171 \\
\hline Ventilation time $(h)$, mean $\pm S D$ & $105 \pm 71$ & $160.5 \pm 88.5$ & $100 \pm 36$ & .001 \\
\hline ICU time (d), mean $\pm \mathrm{SD}$ & $16 \pm 15$ & $15.5 \pm 13.5$ & $16 \pm 16.5$ & .570 \\
\hline In-hospital time (d), mean $\pm \mathrm{SD}$ & $25 \pm 11$ & $21.5 \pm 13.5$ & $27 \pm 10$ & .503 \\
\hline Nasopharyngeal temperature $\left({ }^{\circ} \mathrm{C}\right)$, mean $\pm \mathrm{SD}$ & $24 \pm 3$ & $23 \pm 3$ & $23 \pm 1$ & .181 \\
\hline Rectal temperature $\left({ }^{\circ} \mathrm{C}\right)$, mean $\pm \mathrm{SD}$ & $26 \pm 2$ & $26 \pm 2$ & $26 \pm 2.5$ & .655 \\
\hline Transfused RBC units, $\mathrm{n}$ & & & & .739 \\
\hline$\leq 10$ & 30 & 11 & 19 & \\
\hline $11-20$ & 57 & 23 & 34 & \\
\hline $21-30$ & 33 & 13 & 20 & \\
\hline$>30$ & 15 & 7 & 8 & \\
\hline Transfused serum units, $n$ & & & & .493 \\
\hline$\leq 5$ & 4 & 1 & 3 & \\
\hline $6-10$ & 73 & 31 & 42 & \\
\hline $11-15$ & 44 & 19 & 25 & \\
\hline$>15$ & 14 & 3 & 11 & \\
\hline 30-d mortality, n (\%) & $21(15.6)$ & $12(22.2)$ & $9(11.1)$ & .081 \\
\hline Paraplegia, n (\%) & $3(2.2)$ & $2(3.7)$ & $1(1.2)$ & .564 \\
\hline TND, n (\%) & $7(5.2)$ & $3(5.6)$ & $4(4.9)$ & 1.000 \\
\hline PND, n $(\%)$ & $17(12.6)$ & $9(16.7)$ & $8(9.9)$ & .244 \\
\hline Renal failure, $\mathrm{n}(\%)$ & $23(17.0)$ & $11(20.4)$ & $12(14.8)$ & .400 \\
\hline Tracheostomy, n (\%) & $10(7.4)$ & $5(9.3)$ & $3(3.7)$ & .266 \\
\hline Redo for bleeding, $\mathrm{n}(\%)$ & $3(2.2)$ & $2(3.7)$ & $1(1.2)$ & .564 \\
\hline Mediastinal infection, $\mathrm{n}(\%)$ & $5(3.7)$ & $3(5.6)$ & $2(2.5)$ & .389 \\
\hline
\end{tabular}

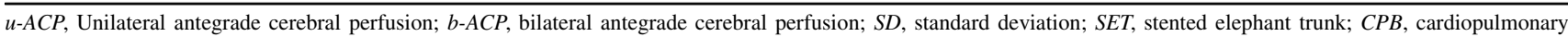
bypass; $I C U$, intensive care unit; $R B C$, red blood cell; $T N D$, temporary neurologic dysfunction; $P N D$, permanent neurologic dysfunction.

the 2 groups $(23.1 \%$ for $\mathrm{u}-\mathrm{ACP}$ vs $18.0 \%$ for $\mathrm{b}-\mathrm{ACP}$; $P=.179)$, Bivariate logistic analysis identified age, preoperative renal dysfunction, CPB time, cross-clamp time, and circulatory arrest time as predictors of postoperative renal failure. Multivariate regression identified age and preoperative renal dysfunction as independent predictors of postoperative renal failure (Table 8 ). The morbidities of redo for bleeding $(4.6 \%$ vs $2.8 \% ; P=.64)$, mediastinal infection $(6.2 \%$ vs $3.7 \% ; P=.478)$, and paraplegia $(3.1 \%$ vs $2.8 \% ; P=1.00)$ were similar in the 2 groups. Major perioperative characteristics and outcomes of patients who underwent surgery within 24 hours of symptom onset are presented in Table 4. In these patients, no significant between-group difference was observed for any parameter except ventilation time $(160 \pm 88.5$ hours vs $100 \pm 36$ hours; $P<.001)$, similar to the result for the whole cohort.

\section{DISCUSSION}

Aortic surgery centers have adopted different cerebral perfusion strategies to optimize operative results and minimize adverse outcomes. ${ }^{17-20}$ Selective ACP has been shown 


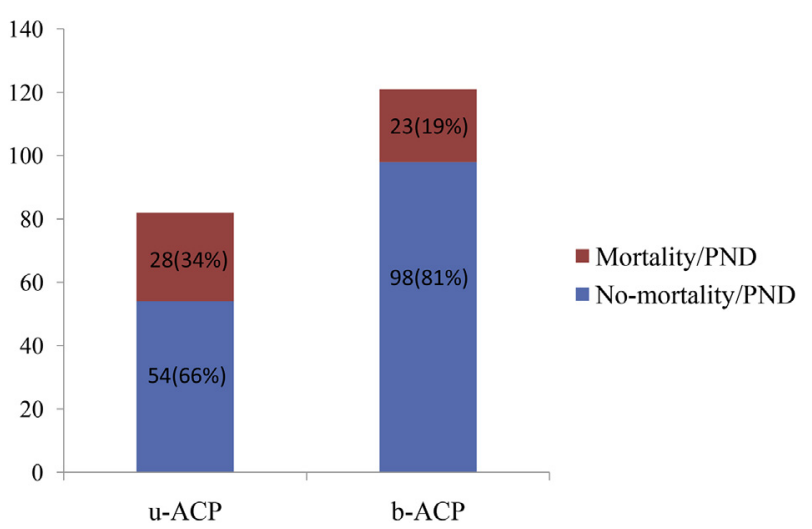

FIGURE 1. Thirty-day mortality and PND in the u-ACP and b-ACP group. $P N D$, Permanent neurological defect; $u-A C P$, unilateral antegrade cerebral perfusion; $b-A C P$, bilateral antegrade cerebral perfusion.

not only to reduce perioperative adverse outcomes, but also to improve long-term outcomes and quality of life. ${ }^{6,21}$ Selective perfusion via the right or left carotid artery provides similarly effective and safe neuroprotection. ${ }^{22}$ The issue of $\mathrm{u}$-ACP versus b-ACP has been examined in aortic arch surgery, but few reports have focused on type A aortic dissection. In the largest report comparing $\mathrm{u}-\mathrm{ACP}$ and b-ACP in aortic surgery but not limited to dissection, enrolling 1002 patients who had undergone partial or total aortic arch repair, Zierer and colleagues ${ }^{23}$ demonstrated that $\mathrm{u}$-ACP offers as much brain and visceral organ protection as b-ACP and may be safer by avoiding manipulation of the arch vessels. In this report, patients with acute type A dissection (347 cases) accounted for $35 \%$ of the study population. In a meta-analysis, Malvindi and colleagues ${ }^{24}$ analyzed 17 reports involving a total of 3548 patients, who underwent 2949 b-ACPs and 599 u-ACPs. They concluded that b-ACP allows for significantly longer ACP time, with increasing safety once ACP time exceeds 40 to 50 minutes.

In a report focusing on type $\mathrm{A}$ aortic dissection, $\mathrm{Lu}$ and colleagues $^{25}$ demonstrated that unilateral ACP via right axillary artery offered brain and visceral protection not inferior to bilateral ACP. In that study, 82 of 263 patients underwent total arch replacement and the other 181 underwent subtotal arch replacement. In a study reported by Preventza and colleagues, ${ }^{15}$ among 157 consecutive patients with type A dissection, mortality and neurologic events were similar in the u-ACP and b-ACP groups. However, the total circulatory arrest time was higher in the b-ACP group, and total circulatory arrest time $>30$ minutes was identified as an independent predictor for stroke in multivariable regression analysis. In that study, the 157 patients included 11 who underwent total arch replacement and 146 who underwent hemiarch replacement.

Traditionally, total arch replacement has been performed in the following scenarios: complex tears for which proximal arch replacement is not sufficient for obliterating the false lumen channel, aneurismal arch, and arch tear. ${ }^{26-28}$ Concomitant carotid arterial dissection is commonly seen in type A aortic dissection. Cerebral malperfusion, most often secondary to this condition, plays a pivotal role in stroke development and is associated with poor outcomes. ${ }^{29,30}$ Trivedi and colleagues ${ }^{8}$ proposed aggressive replacement of the aortic arch for 4 indications, including arch tear, carotid dissection, circumferential arch dissection, and aneusymal arch, and reported excellent outcomes. They also noted a higher rate of neurologic malperfusion in patients undergoing total arch replacement (19.7\%) compared with those undergoing hemiarch replacement $(12.6 \% ; P<.001)$. Preoperative stroke also was more common in patients requiring total arch reconstruction $(14.1 \%$ vs $6.0 \% ; P=.027)$. In this study, an aggressive approach aimed to optimize bilateral carotid perfusion yielded optimal neurologic outcomes. Similar indications for total arch replacement were used in our protocol.

In the present study, we had a total arch replacement rate of $57.8 \%$, which is significantly greater than the rates reported in most published series in North America and Europe but comparable to those in other reports from

TABLE 5. 30-day mortality and morbidity

\begin{tabular}{|c|c|c|c|c|}
\hline Variable & Total $(\mathbf{n}=\mathbf{2 0 3})$ & $\mathbf{u}-\mathbf{A C P}(\mathbf{n}=82)$ & b-ACP $(n=121)$ & $P$ value \\
\hline Ventilation time $(\mathrm{h})$, mean $\pm \mathrm{SD}$ & $101 \pm 73$ & $147.0 \pm 82$ & $95.5 \pm 45.25$ & .000 \\
\hline ICU time (d), mean \pm SD & $17 \pm 14$ & $17 \pm 11.5$ & $16 \pm 17.75$ & .454 \\
\hline In-hospital time (d), mean $\pm \mathrm{SD}$ & $24 \pm 10$ & $23 \pm 8$ & $25 \pm 9$ & .321 \\
\hline 30-d mortality, n (\%) & $31(15.3)$ & $17(20.7)$ & $14(11.6)$ & .075 \\
\hline Paraplegia, n (\%) & $5(2.9)$ & $2(3.1)$ & $3(2.8)$ & 1.000 \\
\hline TND, n (\%) & $11(6.4)$ & $6(9.2)$ & $5(4.7)$ & .236 \\
\hline PND, n (\%) & $20(11.6)$ & $11(16.9)$ & $9(8.4)$ & .091 \\
\hline Renal failure, n (\%) & $31(18.0)$ & $15(23.1)$ & $16(18.0)$ & .179 \\
\hline Tracheostomy, n (\%) & $15(8.7)$ & $11(16.9)$ & $4(3.7)$ & .003 \\
\hline Redo for bleeding, $\mathrm{n}(\%)$ & $6(3.5)$ & $3(4.6)$ & $3(2.8)$ & .64 \\
\hline Mediastinal infection, $\mathrm{n}(\%)$ & $8(4.7)$ & $4(6.2)$ & $4(3.7)$ & .478 \\
\hline
\end{tabular}

All outcomes except mortality are based on a total of 154 patients who survived surgery. $u$ - $A C P$, Unilateral antegrade cerebral perfusion; $b$ - $A C P$, bilateral antegrade cerebral perfusion; $S D$, standard deviation; $I C U$, intensive care unit; $T N D$, temporary neurologic dysfunction; $P N D$, permanent neurologic dysfunction. 
TABLE 6. Risk factors for 30-day mortality

\begin{tabular}{|c|c|c|c|c|}
\hline \multirow[b]{2}{*}{ Risk factor } & \multicolumn{2}{|c|}{ Univariate analysis } & \multicolumn{2}{|c|}{ Multivariate analysis } \\
\hline & OR $(95 \%$ CI $)$ & $P$ value & OR $(95 \%$ CI $)$ & $P$ value \\
\hline Age (y) & $1.150(1.084-1.220)$ & $<.001$ & & \\
\hline Female sex & $0.037(0.013-0.107)$ & $<.001$ & & \\
\hline Renal dysfunction & $0.298(0.102-0.873)$ & .027 & & \\
\hline Acute type A dissection $(<24 \mathrm{~h})$ & $0.181(0.021-1.421)$ & .096 & & \\
\hline COPD & $0.085(0.007-0.966)$ & .047 & & \\
\hline Time to the start of cohort & $1.003(0.983-1.024)$ & .758 & & \\
\hline Pericardial effusion/tamponade & $0.279(0.105-0.741)$ & .010 & & \\
\hline Hemodynamic instability & $0.103(0.030-0.349)$ & $<.001$ & & \\
\hline CABG & $0.401(0.151-1.061)$ & .066 & & \\
\hline CPB time & $1.048(1.027-1.070)$ & $<.001$ & $0.945(0.899-0.994)$ & .028 \\
\hline Cross-clamp time & $1.099(1.053-1.148)$ & $<.001$ & & \\
\hline Circulatory arrest time & $1.446(1.242-1.68)$ & $<.001$ & $0.753(0.595-0.954)$ & .019 \\
\hline
\end{tabular}

$O R$, Odds ratio; $C I$, confidence interval; $C O P D$, chronic obstructive pulmonary disease; $C A B G$, coronary artery bypass grafting; $C P B$, cardiopulmonary bypass.

China. ${ }^{9,31}$ One rationale for the high total arch replacement rate is the relative young age of our patients $(51.0 \pm 13$ years) in contrast to much older counterparts from the International Registry of Aortic Dissection ${ }^{32}$ and the German Registry for Acute Aortic Dissection Type A. ${ }^{7}$ Young age is associated with lower perioperative risk for total arch replacement, ${ }^{15}$ but a high risk of recurrence in the future, ${ }^{33}$ which might be further exacerbated by poor hypertension control in the Chinese population. ${ }^{34}$ Previous studies of similar total replacement rates have reported optimal short- and long-term outcomes with low reintervention rates. ${ }^{9,33}$ We believe that in patients with type A dissection in whom total arch replacement is indicated, an optimal intraoperative cerebral perfusion strategy is mandated to achieve optimal outcomes.

The mortality rate of $14.5 \%$ for our entire series is comparable with rates reported by others. ${ }^{20,25,35}$ Some surgeons are reluctant to use b-ACP because of its complexity. In the present study, we found no increase in cross-clamp time, CPB time, or surgery time in the b-ACP group. Another rationale for avoiding b-ACP cited by some surgeons is the risk of embolic injury by cannulating the left common carotid artery in an atheromatous aorta. In the present study, this risk was avoided by attaching the left common carotid artery to the 4-branched prosthetic graft for left hemisphere perfusion.

In the present study, the rate of PND was similar in the $\mathrm{u}-$ APC and b-APC groups ( $16.9 \%$ vs $8.4 \% ; P=.091)$. b-ACP was not associated with a lower incidence of TND; however, it was associated with shorter mean ventilation time $(95.5 \pm 45.25$ vs $147.0 \pm 82$ hours; $P<.01)$ and lower tracheostomy rate. In our institute, protocols to wean patients from ventilation were normally initiated as soon as consciousness was regained. There was no difference in the occurrence of renal failure between the $\mathrm{u}-\mathrm{ACP}$ and $\mathrm{b}-\mathrm{ACP}$ groups, consistent with previous reports. ${ }^{15,25}$

In our entire series, bivariate logistic regression analysis identified age, female sex, preoperative renal dysfunction, acute type A dissection, pericardial effusion/tamponade, CPB time, cross-clamp time, and circulatory arrest time were predictive of mortality, whereas multivariate regression analysis identified CPB time and circulatory arrest time as independent predictors of mortality. Preventza and colleagues $^{15}$ also identified age and circulatory arrest time, and Khaladj and colleagues ${ }^{36}$ identified age, CPB time, and previous sternotomy, as independent risk factors for mortality. CPB time and circulatory arrest time have been identified as independent predictors of PND. Previous

TABLE 7. Risk factors for PND

\begin{tabular}{|c|c|c|c|c|}
\hline \multirow[b]{2}{*}{ Risk factor } & \multicolumn{2}{|c|}{ Univariate analysis } & \multicolumn{2}{|c|}{ Multivariate analysis } \\
\hline & OR $(95 \%$ CI $)$ & $P$ value & OR $(95 \%$ CI $)$ & $P$ value \\
\hline Age (y) & $1.125(1.051-1.204)$ & .001 & & \\
\hline Acute type A dissection $(<24 \mathrm{~h})$ & $2.431(0.874-8.293)$ & .053 & & \\
\hline Hemodynamic instability & $0.170(0.027-1.090)$ & .062 & & \\
\hline Type of cerebral perfusion & $2.521(0.956-6.644)$ & .062 & & \\
\hline Time to the start of cohort & $0.980(0.954-1.006)$ & .125 & & \\
\hline CPB time & $1.039(1.018-1.060)$ & $<.001$ & $0.957(0.917-0.998)$ & .041 \\
\hline Cross-clamp time & $1.049(1.015-1.084)$ & .004 & & \\
\hline Circulatory arrest time & $1.480(1.224-1.790)$ & $<.001$ & $0.427(0.198-0.921)$ & .030 \\
\hline
\end{tabular}

$P N D$, Permanent neurologic dysfunction; $O R$, odds ratio; $C I$, confidence interval; $C P B$, cardiopulmonary bypass. 
TABLE 8. Risk factors for renal failure

\begin{tabular}{|c|c|c|c|c|}
\hline \multirow[b]{2}{*}{ Risk factor } & \multicolumn{2}{|c|}{ Univariate analysis } & \multicolumn{2}{|c|}{ Multivariate analysis } \\
\hline & OR $(95 \% \mathrm{CI})$ & $P$ value & OR $(95 \%$ CI $)$ & $P$ value \\
\hline Age (y) & $1.135(1.068-1.206)$ & $<.001$ & $1.141(1.037-1.255)$ & .007 \\
\hline Acute type A dissection $(<24 \mathrm{~h})$ & $1.781(0.841-3.541)$ & .251 & & \\
\hline Type of cerebral perfusion & $1.840(0.832-4.071)$ & .132 & & \\
\hline Renal dysfunction & $0.082(0.031-0.219)$ & $<.001$ & $0.030(0.004-0.242)$ & .001 \\
\hline Time to the start of cohort & $1.000(0.980-1.021)$ & .987 & & \\
\hline CPB time & $1.040(1.022-1.059)$ & $<.001$ & & \\
\hline Cross-clamp time & $1.068(1.033-1.103)$ & $<.001$ & & \\
\hline Circulatory arrest time & $1.458(1.238-1.718)$ & $<.001$ & & \\
\hline
\end{tabular}

$O R$, Odds ratio; $C I$, confidence interval; $C P B$, cardiopulmonary bypass.

studies suggested justified use of b-ACP for circulatory arrest times of $>30$ minutes $^{15}$ or up to 40 to 50 minutes $^{24}$; however, the duration of circulatory arrest might be difficult to predict beforehand. In our b-ACP strategy, both cerebral perfusion routes were established before circulatory arrest.

\section{Study Limitations}

This study has some inevitable limitations. First, even though the data were extracted and analyzed form a prospectively maintained database, the study is a retrospective review, and the results may be affected by its nonrandomized design. Second, this study represents only a singlecenter experience and not a multicenter experience. There surely are some disparities among different centers and operators. Third, surgeries for the 2 groups were not performed entirely in the same era.

Although this is one of the largest single-center series to focus on the difference between $\mathrm{u}-\mathrm{ACP}$ and b-ACP in total arch replacement for type A dissection, the patient population is still relatively small, and consequently conclusions can be challenging. Assuming u-ACP and b-ACP at a 1:1 ratio, a sample size of 506 is needed to demonstrate a mortality difference with 0.8 power at $\alpha=0.05$, and at least 236 patients per group are required to demonstrate the PND difference. Finally, changes in cerebral monitoring, anesthetic management, and intensive care unit care may have had an impact on the 2 groups, given the extended duration of our study period.

\section{CONCLUSIONS}

In conclusion, our study, performed exclusively in patients who underwent total arch replacement for type A aortic dissection, showed that b-ACP was not associated with significantly lower 30-day mortality or PND compared with u-ACP. CPB time and circulatory arrest time were identified as independent risk factors for both mortality and PND. b-ACP did not increase CPB, cross-clamp, or circulatory arrest time. Future large sample size, randomized, multicenter studies are warranted to thoroughly compare b$\mathrm{ACP}$ and $\mathrm{u}-\mathrm{ACP}$.

\section{Conflict of Interest Statement}

Authors have nothing to disclose with regard to commercial support.

\section{References}

1. Tsai TT, Trimarchi S, Nienaber CA. Acute aortic dissection: perspectives from the International Registry of Acute Aortic Dissection (IRAD). Eur J Vasc Endovasc Surg. 2009;37:149-59.

2. Apostolakis E, Koletsis EN, Dedeilias P, Kokotsakis JN, Sakellaropoulos G, Psevdi A, et al. Antegrade versus retrograde cerebral perfusion in relation to postoperative complications following aortic arch surgery for acute aortic dissection type A. J Card Surg. 2008;23:480-7.

3. David TE. Surgery for acute type A aortic dissection. J Thorac Cardiovasc Surg. 2015;150:279-83.

4. Kazui T, Yamashita K, Washiyama N, Terada H, Bashar AH, Suzuki K, et al. Aortic arch replacement using selective cerebral perfusion. Ann Thorac Surg. 2007;83:S796-8; discussion S824-31.

5. Olsson C, Thelin S. Antegrade cerebral perfusion with a simplified technique: unilateral versus bilateral perfusion. Ann Thorac Surg. 2006;81:868-74.

6. Immer FF, Moser B, Krähenbühl ES, Englberger L, Stalder M, Eckstein FS, et al. Arterial access through the right subclavian artery in surgery of the aortic arch improves neurologic outcome and mid-term quality of life. Ann Thorac Surg. 2008;85:1614-8; discussion 1618.

7. Rylski B, Hoffmann I, Beyersdorf F, Suedkamp M, Siepe M, Nitsch B, et al. Acute aortic dissection type A: age-related management and outcomes reported in the German Registry for Acute Aortic Dissection Type A (GERAADA) of over 2000 patients. Ann Surg. 2014;259:598-604.

8. Trivedi D, Navid F, Balzer JR, Joshi R, Lacomis JM, Jovin TG, et al. Aggressive aortic arch and carotid replacement strategy for type A aortic dissection improves neurologic outcomes. Ann Thorac Surg. 2016;101:896-903; discussion 903-5.

9. Sun L, Qi R, Zhu J, Liu Y, Zheng J. Total arch replacement combined with stented elephant trunk implantation: a new "standard" therapy for type A dissection involving repair of the aortic arch? Circulation. 2011;123:971-8.

10. Di Bartolomeo R, Pantaleo A, Berretta P, Murana G, Castrovinci S, Cefarelli M, et al. Frozen elephant trunk surgery in acute aortic dissection. J Thorac Cardiovasc Surg. 2015;149:S105-9.

11. Roselli EE, Loor G, He J, Rafael AE, Rajeswaran J, Houghtaling PL, et al. Distal aortic interventions after repair of ascending dissection: the argument for a more aggressive approach. J Thorac Cardiovasc Surg. 2015;149:S117-24.

12. Zierer A, Risteski P, El-Sayed Ahmad A, Moritz A, Diegeler A, Urbanski PP. The impact of unilateral versus bilateral antegrade cerebral perfusion on surgical outcomes after aortic arch replacement: a propensity-matched analysis. J Thorac Cardiovasc Surg. 2014;147:1212-7; discussion 1217-8.

13. Ehrlich MP, Ergin MA, McCullough JN, Lansman SL, Galla JD, Bodian CA, et al. Predictors of adverse outcome and transient neurological dysfunction after ascending aorta/hemiarch replacement. Ann Thorac Surg. 2000;69: 1755-63.

14. Ehrlich MP, Schillinger M, Grabenwöger M, Kocher A, Tschernko EM, Simon P, et al. Predictors of adverse outcome and transient neurological dysfunction following surgical treatment of acute type A dissections. Circulation. 2003; 108:II318-23. 
15. Preventza O, Simpson KH, Cooley DA, Cornwell L, Bakaeen FG, Omer S, et al. Unilateral versus bilateral cerebral perfusion for acute type A aortic dissection. Ann Thorac Surg. 2015;99:80-7.

16. Fukui T, Tabata M, Morita S, Takanashi S. Gender differences in patients undergoing surgery for acute type A aortic dissection. J Thorac Cardiovasc Surg. 2015; 150:581-7.e1

17. Peterson MD, Mazine A, El-Hamamsy I, Manlhiot C, Ouzounian M, MacArthur RG, et al. Knowledge, attitudes, and practice preferences of Canadian cardiac surgeons toward the management of acute type A aortic dissection. $J$ Thorac Cardiovasc Surg. 2015;150:824-31.e1-5.

18. Usui A, Ueda Y. Arch first technique under deep hypothermic circulatory arrest with retrograde cerebral perfusion. Multimed Man Cardiothorac Surg. 2007; 2007:mmcts.2006.001974.

19. Milewski RK, Pacini D, Moser GW, Moeller P, Cowie D, Szeto WY, et al. Retrograde and antegrade cerebral perfusion: results in short elective arch reconstructive times. Ann Thorac Surg. 2010;89:1448-57.

20. Leshnower BG, Myung RJ, Kilgo PD, Vassiliades TA, Vega JD, Thourani VH, et al. Moderate hypothermia and unilateral selective antegrade cerebral perfusion: a contemporary cerebral protection strategy for aortic arch surgery. Ann Thorac Surg. 2010;90:547-54.

21. Immer FF, Lippeck C, Barmettler H, Berdat PA, Eckstein FS, Kipfer B, et al. Improvement of quality of life after surgery on the thoracic aorta: effect of antegrade cerebral perfusion and short duration of deep hypothermic circulatory arrest. Circulation. 2004;110:II250-5.

22. Urbanski PP, Lenos A, Zacher M, Diegeler A. Unilateral cerebral perfusion: right versus left. Eur J Cardiothorac Surg. 2010;37:1332-6.

23. Zierer A, El-Sayed Ahmad A, Papadopoulos N, Moritz A, Diegeler A, Urbanski PP. Selective antegrade cerebral perfusion and mild $\left(28^{\circ} \mathrm{C}-30^{\circ} \mathrm{C}\right)$ systemic hypothermic circulatory arrest for aortic arch replacement: results from 1002 patients. J Thorac Cardiovasc Surg. 2012;144:1042-9.

24. Malvindi PG, Scrascia G, Vitale N. Is unilateral antegrade cerebral perfusion equivalent to bilateral cerebral perfusion for patients undergoing aortic arch surgery? Interact Cardiovasc Thorac Surg. 2008;7:891-7.

25. Lu S, Sun X, Hong T, Yang S, Song K, Lai H, et al. Bilateral versus unilateral antegrade cerebral perfusion in arch reconstruction for aortic dissection. Ann Thorac Surg. 2012;93:1917-20.

26. Trimarchi S, Nienaber CA, Rampoldi V, Myrmel T, Suzuki T, Mehta RH, et al. Contemporary results of surgery in acute type A aortic dissection: the International Registry of Acute Aortic Dissection experience. J Thorac Cardiovasc Surg. 2005;129:112-22.
27. Crawford ES, Kirklin JW, Naftel DC, Svensson LG, Coselli JS, Safi HJ. Surgery for acute dissection of ascending aorta. Should the arch be included? J Thorac Cardiovasc Surg. 1992;104:46-59.

28. Moon MR, Sundt TM III, Pasque MK, Barner HB, Huddleston CB, Damiano RJ Jr, et al. Does the extent of proximal or distal resection influence outcome for type A dissections? Ann Thorac Surg. 2001;71:1244-9; discussion 1249-50.

29. Augoustides JG, Geirsson A, Szeto WY, Walsh EK, Cornelius B, Pochettino A et al. Observational study of mortality risk stratification by ischemic presentation in patients with acute type A aortic dissection: the Penn classification. Nat Clin Pract Cardiovasc Med. 2009;6:140-6.

30. Augoustides JG, Szeto WY, Desai ND, Pochettino A, Cheung AT, Savino JS, et al. Classification of acute type A dissection: focus on clinical presentation and extent. Eur J Cardiothorac Surg. 2011;39:519-22.

31. Wang W, Duan W, Xue Y, Wang L, Liu J, Yu S, et al. Clinical features of acute aortic dissection from the Registry of Aortic Dissection in China. J Thorac Cardiovasc Surg. 2014;148:2995-3000.

32. Trimarchi S, Eagle KA, Nienaber CA, Rampoldi V, Jonker FH, De Vincentiis C et al. Role of age in acute type A aortic dissection outcome: report from the International Registry of Acute Aortic Dissection (IRAD). J Thorac Cardiovasc Surg. 2010;140:784-9.

33. Omura A, Miyahara S, Yamanaka K, Sakamoto T, Matsumori M, Okada K, et al Early and late outcomes of repaired acute DeBakey type I aortic dissection after graft replacement. J Thorac Cardiovasc Surg. 2016;151:341-8.

34. Wang J, Ning X, Yang L, Lu H, Tu J, Jin W, et al. Trends of hypertension prevalence, awareness, treatment and control in rural areas of northern China during 1991-2011. J Hum Hypertens. 2014;28:25-31.

35. Wiedemann D, Kocher A, Dorfmeister M, Vadehra A, Mahr S, Laufer G et al. Effect of cerebral protection strategy on outcome of patients with Stanford type A aortic dissection. J Thorac Cardiovasc Surg. 2013;146: 647-55.e1.

36. Khaladj N, Shrestha M, Meck S, Peterss S, Kamiya H, Kallenbach K, et al. Hypothermic circulatory arrest with selective antegrade cerebral perfusion in ascending aortic and aortic arch surgery: a risk factor analysis for adverse outcome in 501 patients. J Thorac Cardiovasc Surg. 2008;135: 908-14.

Key Words: antegrade cerebral perfusion, circulatory arrest, total arch replacement, type A aortic dissection 